\title{
MANEJO DA IRRIGAÇÃO NA INCIDÊNCIA DA BROCA-DO-CAFÉ ${ }^{1}$
}

\author{
Jonas Françoso ${ }^{2}$, Adriano Augusto de Paiva Custódio ${ }^{3}$, Jair Campos Moraes ${ }^{2}$, Luiz Antônio \\ Lima $^{4}$, Manoel Alves de Faria ${ }^{5}$, Anselmo Augusto de Paiva Custódio ${ }^{6}$ \\ ${ }^{1}$ Projeto financiado pelo PNP\&D/CAFÉ - EMBRAPA. \\ ${ }^{2}$ Departamento de Entomologia da UFLA, C.P.3037, CEP 37200-000, Lavras, MG. E-mail: jcmoraes@ den.ufla.br \\ ${ }^{3}$ Departamento de Fitopatologia da UFLA, C.P.3037, CEP 37200-000, Lavras, MG. \\ ${ }^{4,5}$ Departamento de Engenharia da UFLA, C.P 3037, CEP 37200-000, Lavras, MG. \\ ${ }^{6}$ Departamento de Produção Vegetal da UNESP, CEP 14.883-390, Jaboticabal, SP.
}

\section{RESUMO}

O objetivo neste trabalho foi verificar a incidência da broca-do-café Hypothenemus hampei (Ferrari, 1867) (Coleoptera: Scolytidae) em lavoura irrigada por gotejamento e por pivô central, em diferentes manejos. Foram realizados dois experimentos, em duas lavouras cafeeiras de Coffea arabica, irrigadas pelo método de aspersão tipo pivô central e localizado tipo gotejamento. Os experimentos foram conduzidos com delineamento em blocos ao acaso, com três repetições na lavoura irrigada por aspersão e quatro repetições na lavoura com irrigação localizada. Os tratamentos corresponderam aos diferentes manejos de irrigação, sendo na lavoura irrigada por pivô central composta por seis níveis de lâminas de água $(\% \mathrm{Kc})$ e na lavoura irrigada por gotejamento composta por cinco manejos, baseado nos diferentes meses do ano e no consumo de água pelas plantas. Fez-se a avaliação do inseto-praga amostrando-se 64 frutos em cada parcela, em três épocas do ano agrícola 2009/2010. Foram constatadas influências significativas dos tratamentos na lavoura irrigada por pivô central nas avaliações de início de novembro de 2009 e início de março de 2010 . Houve $27,00 \%$ de infestação da broca-do-café na lâmina de $60 \%$ do coeficiente da cultura $(\mathrm{Kc})$ referente ao início de novembro de 2009. Já na avaliação referente ao início do mês de março de 2010, foi observada maior incidência da broca nos tratamentos não irrigados $(11,98 \%)$ e na lâmina de $60 \%$ do Kc $(12,50 \%)$. Não houve diferença significativa entre os tratamentos na lavoura irrigada por gotejamento, quanto à infestação da broca, nas três épocas do ano. Houve maior incidência da broca-do-café na lavoura irrigada pelo método da aspersão tipo pivô central.

Palavras-chave: Hypothenemus hampei, Coffea arabica, MIP

\section{IRRIGATION MANAGEMENT IN INCIDENCY COFFEE BERRY BORER}

\section{ABSTRACT}

The objective of this work was to evaluate the incidence of coffee berry borer in irrigated farming and drip with a pivot on different managements. Two experiments were conducted in two coffee plantations of Coffea arabica, irrigated by the method of center pivot sprinkler or by localized drip. The experimental design was randomized blocks with three replications in the fields irrigated by sprinkler and four replications in fields with drip irrigation. The treatments consisted of different irrigation managements, at the crop being irrigated by center pivot consisted of six levels of water level $(\% \mathrm{Kc})$ and for drip irrigated farming managements consisted of ones, based on the different months of the year and water consumption by plants. The insects were evaluate by sampling 64 coffee fruits (berries) from each plot, three times in the 
season 2009/2010. We found significant influences of the treatments in the fields irrigated by center pivot in evaluations of early November 2009 and early March 2010. There was 27.00\% infestation of the coffee berry borer in the water level $60 \%$ of crop coefficient $(\mathrm{Kc})$ for the beginning of November 2009. In the assessment for the beginning of March 2010, it was observed higher incidence of the drill in non-irrigated treatments $(11.98 \%)$ and $60 \%$ of the water level Kc $(12.50 \%)$. There was no significant difference between treatments in the fields irrigated by drip, on the borer infestation in the three sampled times. There was a higher incidence of the coffee berry borer in irrigated farming by the method of center pivot sprinkler.

Key words: Hypothenemus hampei, Coffea arabica, IPM

\section{INTRODUÇÃO}

O Brasil detém maior competitividade na produção de café que a maioria de seus concorrentes. Esse fato é atribuído ao maior uso de tecnologias, à maior escala de produção e às melhores condições de solo e de clima. No entanto, a produtividade média brasileira de 19,5 sacas ha $^{-1}$, está ainda muito aquém de seu potencial produtivo (Agrianual, 2007).

$\mathrm{O}$ cafeeiro foi tradicionalmente cultivado em áreas com condições pluviométricas favoráveis ao seu crescimento e desenvolvimento. Entretanto, essa cultura vem sendo cada vez mais incorporada a áreas mecanizáveis, embora com escassez hídrica. Assim, a irrigação nessas localidades tem se mostrado vantajosa (Gomes et al., 2007). Vários são os métodos de irrigação utilizados para suprir a demanda de água das plantas, destacando-se o localizado, tipo gotejamento e por aspersão, tipo pivô central.

Uma cultura, quando irrigada, fica submetida a um microclima diferenciado em relação ao cultivo em regime de sequeiro. Isso resulta em características peculiares em relação aos aspectos fitossanitários, incluindo aqueles relacionados ao ataque de insetos-praga responsáveis por perdas na lavoura, como a broca-do-café. Assim, para as culturas irrigadas devem ser realizados estudos que relacionem níveis e manejos de aplicação de água e suas variações apresentadas com relação aos insetos-praga (Meireles et al., 2001; Custódio et al., 2009).

A broca-do-café Hypothenemus hampei (Ferrari, 1867) (Coleoptera: Scolytidae) é um dos fatores que contribuem para reduzir a produtividade na cafeicultura, provocando danos diretos na produção (Mathieu et al., 1998; Jaramillo et al., 2006). É considerada praga chave na maioria dos países produtores dessa bebida (Ferreira, 2000), sendo ainda uma das principais pragas da cultura em todo o mundo. Dependendo do nível de infestação, os prejuízos devido à perda de peso podem chegar a $21 \%$ e também em conseqüência do ataque as sementes, a qualidade do café fica prejudicada (Souza \& Reis, 1997). Conforme Benassi \& Benassi (2000), a broca se alimenta e reproduz em todas as espécies do gênero Coffea, atacando os frutos de todos os estádios, desde os verdes até os maduros e secos causando perdas quantitativas e qualitativas consideráveis. Segundo Gallo et al. (2002), o ciclo da broca-do-café desde a postura até a emergência do adulto completa-se em 27 a 30 dias, em média, durando as fases de ovo, larva e pupa, respectivamente, 4 a 10, 14 e 7 dias, com três gerações a campo.

Dessa forma, o entendimento de como o ambiente pode favorecer a ocorrência de pragas permitirá conhecer métodos de controle que visem a redução dessas perdas na lavoura, gerando informações relevantes sobre o manejo eficaz da água de irrigação. Isso contribuirá 
com a redução de impactos ambientais, pela adequada utilização da água de irrigação na agricultura e no correto controle fitossanitário devido ao melhor posicionamento de inseticidas no campo. Nesse contexto, o objetivo deste trabalho foi verificar a incidência da broca-do-café, em lavoura irrigada pelo método da aspersão tipo pivô central e localizado tipo gotejamento, em diferentes manejos.

\section{MATERIAL E MÉTODOS}

Foram realizados dois experimentos na área do Departamento de Engenharia da Universidade Federal de Lavras, na latitude $21^{\circ} 13^{\prime}$ Sul, longitude $44^{\circ} 58^{\prime}$ ' Oeste e altitude média de $910 \mathrm{~m}$. Para isso, foram utilizadas duas lavouras cafeeiras da cultivar Rubi "MG 1192" e Acaiá - "MG 1474" (Coffea arabica L.), irrigadas desde o início, respectivamente, pelo método da aspersão tipo pivô central e localizado tipo gotejamento. A lavoura de Rubi foi implantada em março de 1999 no espaçamento de $3,5 \mathrm{~m}$ entre as linhas e $0,8 \mathrm{~m}$ entre as plantas. Já a lavoura de Acaiá foi implantada em março de 1997 no espaçamento de 3,0 m entre as linhas e 0,6 m entre as plantas, sendo recepada em outubro de 2004. O solo da área foi classificado como Latossolo Vermelho Escuro, de textura muito argilosa (Custódio et al., 2009).

$\mathrm{O}$ delineamento utilizado foi $\mathrm{em}$ blocos ao acaso, com três repetições na lavoura irrigada por aspersão e quatro repetições na lavoura com irrigação localizada possuindo, cada parcela, oito plantas úteis. Os tratamentos corresponderam aos diferentes manejos de irrigação na lavoura irrigada por pivô central, sendo lâminas de $0 \%$ (não irrigado), $60 \%, 80 \%, 100 \%, 120 \%$ e $140 \%$ de valores pré-definidos de coeficiente da cultura $(\mathrm{Kc})$ (janeiro-março $=1,10 ;$ abril-julho $=0,90 ;$ agosto-outubro $=1,30$ e novembrodezembro=1,15). Na lavoura irrigada por gotejamento, os tratamentos utilizados foram em função dos diferentes meses do ano e do consumo de água pelas plantas, sendo: $\mathrm{A}=$ testemunha (não irrigado); $\mathrm{B}=$ irrigação $\mathrm{o}$ ano todo sempre que o teor da água disponível no solo (AD) igual a $25 \%$ da disponibilidade total de água (DTA); $\mathrm{C}=$ irrigação o ano todo sempre que $\mathrm{AD} \leq 75 \%$ DTA; D= irrigação o ano todo, quando, em janeiro, fevereiro, março, julho, outubro, novembro e dezembro $\mathrm{AD} \leq 75 \%$ DTA e em abril, maio, junho, agosto e setembro, quando $\mathrm{AD} \leq 25 \%$ DTA e $\mathrm{E}=$ irrigação em abril, maio, junho, agosto e setembro, quando $\mathrm{AD} \leq 75 \%$ DTA.

Foram realizadas três avaliações da broca em frutos do café, em cada lavoura cafeeira, em três épocas do ano. As amostragens foram realizadas no final do mês de julho (após a colheita) de 2009, no início de novembro (frutos no estádio chumbinho) de 2009 e início de março (enchimento dos grãos) de 2010, amostrando-se no máximo 64 frutos por parcela. Na primeira e na segunda avaliação, foi realizada a amostragem de frutos caídos, no solo das parcelas, respectivamente, no final do mês de julho e no início do mês de novembro de 2009. A terceira avaliação da broca em frutos foi realizada nas plantas no início do mês março de 2010, pelo método destrutivo, sendo para isso coletado aleatoriamente oito frutos, em ramos plagiotrópicos do terço médio de cada planta. Em seguida, as amostras foram levadas ao laboratório para contagem da incidência de frutos brocados, conforme realizado por Ferreira et al. (2000).

$\mathrm{Na}$ lavoura irrigada por pivô central, a área irrigada correspondeu a 1,6 ha, contendo dois vãos que totalizaram 67,5 metros de extensão e um lance em balanço de 4 metros, perfazendo um raio molhado de 71,5 metros. O pivô central foi equipado com emissores tipo difusor, distanciados, aproximadamente, 2,20 m entre si e 2,0 m das copas das plantas. A lâmina de água 
aplicada foi definida em função da evapotranspiração acumulada no período entre as irrigações. Foi adotado turno de rega fixo, realizada às segundas, quartas e sextasfeiras. A evapotranspiração da cultura foi obtida a partir da evaporação do tanque Classe "A" (ECA), de acordo com as exigências hídricas da cultura sugeridas por Santinato et al. (2008). Foram considerados, para o cálculo da irrigação, os coeficientes do tanque, da cultura $(\mathrm{Kc})$ e a precipitação que ocorreu no período. Quando o balanço entre a ECA e a precipitação foi nulo ou a favor das precipitações, não foram realizadas irrigações. As diferentes lâminas de água, correspondentes aos tratamentos, foram controladas mediante o ajuste da velocidade do pivô. No tratamento não irrigado, o pivô central deslocou sobre as parcelas, sem aplicar água. A fonte de água utilizada na irrigação da lavoura foi proveniente de uma barragem situada nas proximidades.

$\mathrm{Na}$ lavoura irrigada por gotejamento, com área aproximada de 0,16 ha, a água foi distribuída às plantas por meio de gotejadores autocompensantes (150 a 400 $\mathrm{kPa})$ distanciados $0,40 \mathrm{~m}$ entre si, proporcionando uma faixa molhada de 3,6 $\mathrm{m}^{2}$ com pressão de serviço de $300 \mathrm{kPa}(30$ mca) e vazão de 4,0 $1 \mathrm{~h}^{-1}$. A água utilizada foi proveniente de uma barragem situada a $350 \mathrm{~m}$ da área experimental, onde se encontra uma unidade de bombeamento. Todos os tratamentos, exceto a testemunha, receberam adubação por meio de fertirrigação. $\mathrm{O}$ adubo foi aplicado durante os meses de outubro a março, em três a quatro parcelamentos.

Os tratos culturais nas duas lavouras foram feitos de maneira convencional, sempre que necessário. Na lavoura irrigada por pivô central, as adubações foram realizadas com base nos resultados da análise química do solo, complementadas conforme o laudo da análise química foliar e interpretadas de acordo com Santinato et al. (2008). Nas parcelas onde foi avaliada a incidência do inseto-praga, não foram realizadas aplicações de produtos fitossanitários. $\mathrm{Na}$ lavoura irrigada por gotejamento, foi realizada uma aplicação de fungicida (epoxiconazol + piraclostrobina 1,0 $1 \mathrm{ha}^{-1}$ ) em 07/10/2009, visando o controle de doenças. A quantidade de adubo aplicado e o parcelamento foram iguais para todos os tratamentos, que foi determinada mediante análise química do solo e previsão de safra futura. As adubações foram complementadas conforme o laudo da análise química de folha. As interpretações das análises químicas de folha e de solo seguiram a recomendação de Ribeiro et al. (1999). Os dados climatológicos foram coletados na estação climatológica de Lavras, a uma distância máxima de $570 \mathrm{~m}$ das lavouras. Os dados corresponderam aos valores diários, obtidos da média de, pelo menos, três das quatro observações meteorológicas, de acordo com o Tempo Médio de Greenwich. $\mathrm{O}$ período de monitoramento foi compreendido conforme a mesma época da avaliação da broca. Os dados obtidos foram das variáveis temperaturas máxima, média e mínima $\left({ }^{\circ} \mathrm{C}\right)$, insolação (horas/dia), umidade relativa do ar (\%) e precipitação pluviométrica $(\mathrm{mm})$.

A análise de variância foi realizada a $5 \%$ de probabilidade $(p<0,05)$, pelo teste de comparação de médias de Scott-Knott. Para isso, utilizou-se o programa Sisvar ${ }^{\circledR}$ (Ferreira, 2000) versão 4.0. Foram realizadas as análises de variância da broca-do-café em função dos diferentes manejos de irrigação, em cada época de amostragem, para cada experimento de forma isolada.

\section{RESULTADOS E DISCUSSÃO}

Não houve diferença significativa da incidência da broca-do-café nos frutos em cafés caídos no solo, no período pós-colheita (Tabela 1). Estes resultados podem ter ocorrido devido à remoção do inseto-praga 
Tabela 1. Incidência da broca do café (Hypothenemus hampei) em lavoura cafeeira (Coffea arabica) irrigada pelo método da aspersão tipo pivô central, sob diferentes lâminas de irrigação (\%Kc). UFLA, Lavras, MG, 2011.

\begin{tabular}{lccc}
\hline \hline \multirow{2}{*}{ Lâminas de irrigação $(\% \mathrm{KC})$} & \multicolumn{3}{c}{ Incidência da broca do café (\%) } \\
\cline { 2 - 4 } & $\begin{array}{c}\text { Julho de 2009 } \\
\text { (após a colheita) }\end{array}$ & $\begin{array}{c}\text { Novembro de 2009 } \\
\text { (estádio de chumbinho) }\end{array}$ & $\begin{array}{c}\text { Março de 2010 } \\
\text { (enchimento dos grãos) }\end{array}$ \\
\hline 0 (Testemunha) & $7,29 \mathrm{a}$ & $10,94 \mathrm{a}$ & $11,98 \mathrm{~b}$ \\
60 & $7,29 \mathrm{a}$ & $26,56 \mathrm{~b}$ & $16,67 \mathrm{~b}$ \\
80 & $6,77 \mathrm{a}$ & $8,33 \mathrm{a}$ & $1,56 \mathrm{a}$ \\
100 & $9,38 \mathrm{a}$ & $14,58 \mathrm{a}$ & $2,08 \mathrm{a}$ \\
120 & $11,46 \mathrm{a}$ & $7,29 \mathrm{a}$ & $1,04 \mathrm{a}$ \\
140 & $15,11 \mathrm{a}$ & $14,58 \mathrm{a}$ & $4,69 \mathrm{a}$ \\
\hline Média & 9,55 & 13,72 & 6,34 \\
\hline CV $(\%)$ & 47,85 & 19,08 & 52,03 \\
\hline \hline
\end{tabular}

Médias seguidas pela mesma letra na coluna, que comparam as lâminas de irrigação em cada época de avaliação, não diferem entre si pelo teste de Scott-Knott $(p<0,05)$.

com a colheita do café, associado às altas precipitações pluviométricas ocorridas entre os meses de janeiro e julho de 2009 do período em questão (Figura 1).

De maneira geral, chuvas freqüentes e áreas sujeitas ao acúmulo de água na superfície do solo podem dificultar a proliferação da broca-do-café (Teixeira et al., 2006). Assim, no mesmo período, foram registrados altos índices pluviométricos, com precipitação total de $695,8 \mathrm{~mm}$. Essas condições podem ter desfavorecido a proliferação da broca na lavoura, justificando a ausência da influência das diferentes lâminas de irrigação por aspersão (Figura 1). Ao contrário, Souza \& Reis (1997) observaram que a estiagem prolongada, ocorrida de janeiro a março de 1984, favoreceu a multiplicação da brocado-café. No ano seguinte (1985), quando as chuvas voltaram ao regime normal de outubro a março não houve mais que 5\% dos frutos brocados. Constatou-se incidência média entre os tratamentos na lavoura irrigada por pivô central de 9,55\%, em julho de 2009 (Tabela 1), havendo assim índices superiores a 5\% de infestação, estabelecido como nível de dano econômico.
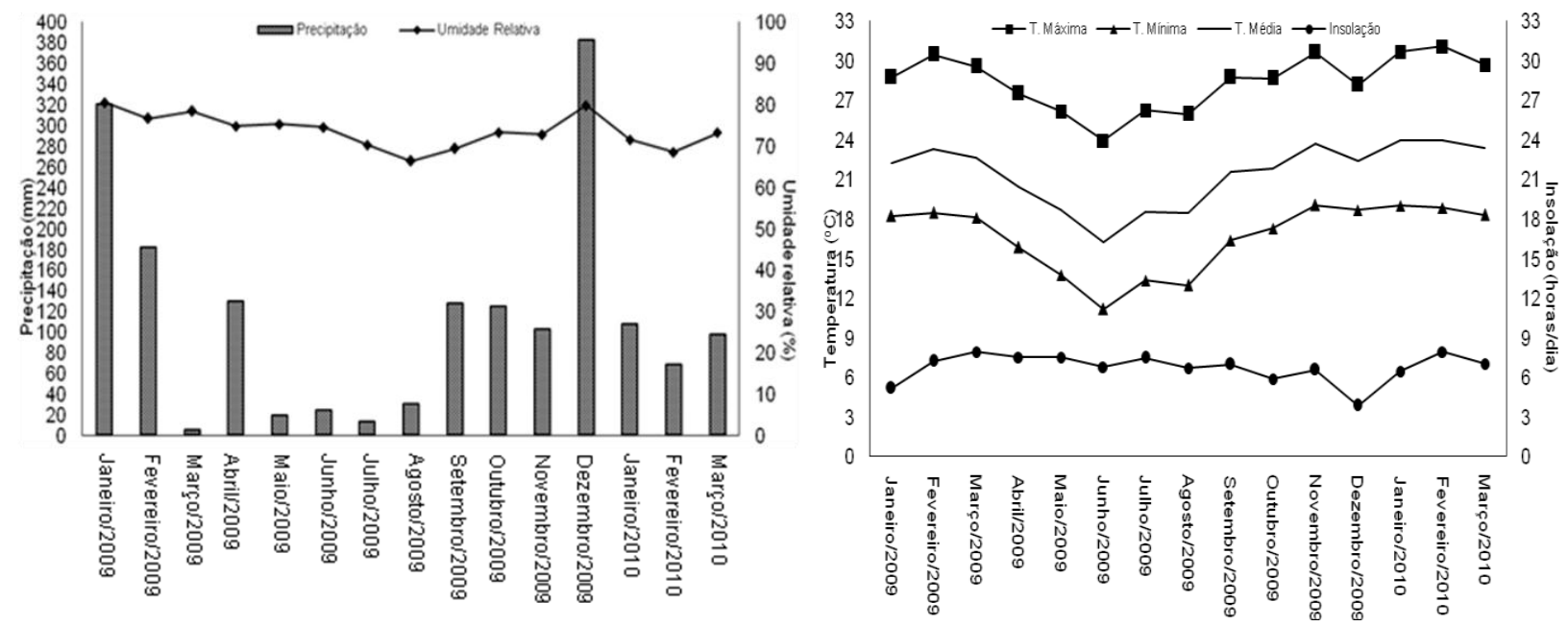

Figura 1. Variáveis climatológicas no período de janeiro de 2009 a março de 2010. UFLA, Lavras, MG, 2010. 
Desta forma, Teixeira et al. (2006) argumentam a incorporação da bioecologia da broca-do-café em frutos dispersos na superfície do solo, na determinação de ações de manejo integrado para o controle da broca-do-café.

Houve diferença significativa entre os tratamentos na avaliação da incidência da broca-do-café em frutos caídos no solo, no início de novembro. Constatou-se maior incidência de infestação na lâmina de $60 \%$ do Kc, de $27 \%$. Foram registrados nos demais tratamentos índices entre $7 \%$ na lâmina de $120 \%$ do $\mathrm{Kc}$ e $14,58 \%$ nas lâminas de 100 e $140 \%$. O índice médio de incidência, em todos os tratamentos, foi de $13,72 \%$ (Tabela 1).

No período de agosto a novembro de 2009 ocorreu baixa precipitação total $(385,5$ $\mathrm{mm}$ ), o que pode ter favorecido o inseto proveniente de frutos brocados deixados no solo. Segundo Backer et al. (1992), há indicações de que a broca consiga permanecer durante todo o período de entressafra do café abrigada em frutos remanescentes na planta e nos frutos caídos ao solo.

Houve influência significativa das diferentes lâminas de irrigação no início do mês de março de 2010, na incidência da broca em frutos coletados nos ramos plagiotrópicos da planta (Tabela 1). Nessa mesma época de avaliação, os índices médios de incidência foram de $6,34 \%$, sendo observada menor incidência do inseto-praga nas maiores lâminas de irrigação, com índices inferiores a $5 \%$ de incidência. Houve nessa época do ano, maior incidência da broca do café nos tratamentos não irrigado $(11,98 \%)$ e na lâmina de $60 \%$ do Kc $(12,50 \%)$. Esta queda na incidência de frutos brocados pode estar associada ao que foi observado por Backer et al. (1992), onde, o volume de chuvas é considerado fator preponderante para que adultos da broca do café deixem os frutos em que se abrigaram na entressafra e colonizem os frutos na nova safra, pois umidade relativa abaixo de $90 \%$ inibe a saída dos adultos dos frutos.

Em estudo realizado por Gomes et al. (2007) no mesmo local do presente experimento, os autores observaram que a lâmina de $60 \%$ da ECA apresentou acréscimo significativo na produtividade do cafeeiro. Por razões técnicas e econômicas, esta lâmina, deve ser adotada pelos cafeicultores da região de Lavras para irrigar a lavoura cafeeira, quando se utiliza pivô central para suprir a demanda hídrica das plantas (Gomes et al., 2007). Desta forma, o histórico de maior carga pendente nesse tratamento pode ter contribuído na maior infestação do inseto-praga. Ainda, segundo Fanton (2001), a irrigação além de propiciar às plantas melhores condições de desenvolvimento e produção de frutos, também aumenta a velocidade de decomposição dos frutos caídos ao solo, privando a broca-do-café de um local de refúgio. Porém, a presença da água fornecida pela irrigação, possivelmente, não só garante a formação, granação e enchimento dos grãos, evitando assim o aparecimento de grãos chochos e mal granados (Santinato et al., 2008), como também modifica o microclima, alterando as condições do ambiente, tais como a temperatura foliar, a umidade relativa do ar do solo. Essa modificação microclimática, por sua vez, pode favorecer o surgimento da broca-docafé (Staver et al., 2001; Soto-Pinto et al., 2002).

Não houve diferença significativa da incidência da broca nos frutos de café quanto aos diferentes manejos de irrigação pelo método de gotejamento, referente ao período pós-colheita, estádio de chumbinho e enchimento dos grãos, no ano agrícola 2008/2009 (Tabela 2).

Souza \& Reis (1997) relatam que a umidade favorece a reprodução da broca-docafé, sendo as lavouras irrigadas durante todo o ano mais propícias ao ataque desse inseto-praga. 
Esse resultado não foi observado na lavoura com irrigação localizada tipo gotejamento. Segundo Ferreira et al. (2000), foram encontradas galerias abandonadas ao redor de $38 \%$ em janeiro e $23 \%$ em fevereiro, que foram declinando até níveis de 7 a $9 \%$ no final da safra.

Ainda segundo os autores, foi observado que um grande número de fêmeas iniciava a construção de galerias, mas abandonava os frutos não chegando a fazer posturas (galerias abandonadas). Assim, um dos motivos para este abandono pode ser devido ao estádio de desenvolvimento dos frutos e também por influência das chuvas (Ferreira et al., 2000), devido a precipitação elevada $(695,8 \mathrm{~mm})$ no período de janeiro a julho de 2009 (Figura 1).

Também, o baixo percentual de frutos brocados deve-se aos cuidados de repasse observado da lavoura. Assim, não permanecendo frutos de um ciclo para o outro servindo como local de hospedagem do inseto-praga, não haveria possibilidade de infestação.

Este resultado pode estar relacionado com os de Cure et al. (1998), que afirmaram que a fonte inicial do inóculo provém dos frutos secos que permaneceram da colheita anterior. Segundo esses autores, em experimento realizado em Paulo
Cândido/MG, em 4 de novembro de 1992, quando a maior parte dos frutos estava no estádio de chumbinho, apenas os frutos secos da safra anterior apresentavam-se brocados, o que demonstra a importância de um repasse bem feito para diminuir as fontes iniciais do inóculo.

Ferreira et al. (2000) concluíram que a influência das chuvas ocorre de forma direta, impedindo ou reduzindo o tempo de vôo na busca de frutos para postura, ou dificultando a construção dos orifícios de penetração do inseto no fruto.

Segundo os autores, isso ocorre porque a umidade excessiva no seu interior contribui para o apodrecimento das lojas do fruto e também possibilita $o$ ataque de fungos entomopatogênicos. Baixos percentuais de broca-do-café podem ser explicados devido à presença de inimigos naturais, principalmente predadores generalistas que são abundantes em plantações de cafeeiros rústicos tais como formigas, aranhas ou aves (Perfecto et al. 1996). As elevadas precipitações ocorridas no período de dezembro de 2009 a março de $2010(656,2 \mathrm{~mm})$ podem ter impedido a proliferação do inseto, evitando que atacassem outros frutos.

Tabela 2. Incidência da broca do café (Hypothenemus hampei) em lavoura cafeeira (Coffea arabica) irrigada pelo método localizado tipo gotejamento, sob diferentes manejos. UFLA, Lavras, MG, 2011.

\begin{tabular}{lccc}
\hline \multirow{2}{*}{ Fonte de Variação } & \multicolumn{3}{c}{ Incidência da broca do café (\%) } \\
\cline { 2 - 4 } & $\begin{array}{c}\text { Julho de 2009 } \\
\text { (após a colheita) }\end{array}$ & $\begin{array}{c}\text { Novembro de 2009 } \\
\text { (estádio de chumbinho) }\end{array}$ & $\begin{array}{c}\text { Março de 2010 } \\
\text { (enchimento dos grãos) }\end{array}$ \\
\hline Manejo A (Testemunha) & $1,17 \mathrm{a}$ & $6,25 \mathrm{a}$ & $1,17 \mathrm{a}$ \\
Manejo B & $3,52 \mathrm{a}$ & $6,25 \mathrm{a}$ & $3,13 \mathrm{a}$ \\
Manejo C & $3,52 \mathrm{a}$ & $3,52 \mathrm{a}$ & $0,78 \mathrm{a}$ \\
Manejo D & $1,56 \mathrm{a}$ & $7,81 \mathrm{a}$ & $1,56 \mathrm{a}$ \\
Manejo E & $0,78 \mathrm{a}$ & $5,86 \mathrm{a}$ & $3,52 \mathrm{a}$ \\
\hline Média & 2,11 & 5,94 & 2,03 \\
\hline CV $(\%)$ & 117,71 & 46,88 & 76,13 \\
\hline \hline
\end{tabular}

Médias seguidas pela mesma letra na coluna, que comparam os manejos de irrigação em cada época de avaliação, não diferem entre si pelo teste de Scott-Knott $(p<0,05)$. 


\section{CONCLUSÕES}

Houve maior incidência da broca-docafé na lavoura irrigada pelo método da aspersão tipo pivô central, comparada à lavoura irrigada pelo método localizado tipo gotejamento.

$\mathrm{Na}$ avaliação realizada no estádio de chumbinho, foi registrada maior incidência da broca-do-café $(26,56 \%)$ na lâmina de irrigação por pivô central de $60 \% \mathrm{Kc}$ e menor nas lâminas de 0, 80, 100, $120 \mathrm{e}$ $140 \%$ Kc. Na avaliação realizada no estádio de enchimento dos grãos, houve maior incidência da broca no tratamento não irrigado $(11,98 \%)$ e na lâmina de $60 \%$ do Kc $(16,67 \%)$ e menor nas demais lâminas de irrigação por pivô central.

\section{REFERÊNCIAS BIBLIOGRÁFICAS}

AGRIANUAL. Anuário da Agricultura Brasileira. São Paulo: FNP Consultoria e Agroinformativos, 2007. 518p.

BAKER, P.S.; LEY, C.; BALBUENA, R.; BARRERA, J.F. Factors affecting the emergence of Hypothenemus hampei (Coleoptera, Scolytidae) from coffee berries. Bulletim of Entomological Research, v.82, n.2, p.145-150, 1992.

BENASSI, V.L.R.M.; BENASSI, A.C. Desenvolvimento da Broca-do-café Hypothenemus hampei (Ferrari, 1867) (Coleoptera: Scolytidae), com frutos de diferentes graus de umidade de Coffea arabica e Coffea canephora. In: SIMPÓSIO DE PESQUISA DOS CAFÉS DO BRASIL 1., 2000, Poços de Caldas. Anais...DF: Embrapa Café, 2000.

Resumos... v.2. p.1204-1206.

CURE, J.R.; SANTOS, R.H.S.; MORAES, J.C.; VILELA, E.F.; GUTIERREZ, A.P. Fenologia e dinâmica populacional da broca do café Hypothenemus hampei (Ferr.) relacionadas às fases de desenvolvimento do fruto. Anais da
Sociedade Entomologica do Brasil. Londrina, v.27, n.3, p.325-335, 1998.

CUSTÓDIO, A.A.P.; MORAES, J.C.; CUSTÓDIO, A.A.P.; LIMA, L.A.; FARIA, M.A. de; GOMES, N.M. Incidência do bicho-mineiro do cafeeiro em lavoura irrigada sob pivô central. Coffee Science, Lavras, v.4, n.1, p.1626, jan./jun.2009.

FANTON, C.J. Ecologia da broca-do-café Hypothenemus hampei (Ferrari, 1867) (Coleoptera: Scolytidae) na Zona da Mata de Minas Gerais. 2001. 49p. Tese (Doutorado em Entomologia) Universidade Federal de Viçosa, Viçosa, 2001.

FERREIRA, A.J.; BUENO, V.H.P.; MORAES, J.C.; CARVALHO, G.A.; BUENO FILHO, J.S.S. Dinâmica populacional da Broca do Café Hypothenemus hampei (Ferr.) (Coleoptera: Scolytidae) em Lavras, MG. Anais da Sociedade Entomológica do Brasil, Lavras, v.29, n.2, p.237-244, 2000.

FERREIRA, D.S. Análise estatística por meio do programa SISVAR para windows versão 4.0. In: REUNIÃO ANUAL DA REGIÃO BRASILEIRA DA SOCIEDADE INTERNACIONAL DE BIOMETRIA, 45., 2000, São Carlos. Anais... São Carlos: UFScar, 2000. p. 255-258.

GALLO, D.; NAKANO, O.; SILVEIRA NETO, S.; CARVALHO, R.P.L.; BATISTA, G.C.; BERTI FILHO, E.; PARRA, J.R.P.; ZUCCHI, R.A.; ALVES, S.B.; VENDRAMIM, J.D.; MARCHINI, L.C.; LOPES, J.R.S.; OMOTO, C. Entomologia agrícola. Piracicaba: FEALQ, 2002. v.10, 920p.

GOMES, N.M.; LIMA, L.A.; CUSTÓDIO, A.A.P. Crescimento vegetativo e produtividade do cafeeiro irrigado no sul do Estado de Minas Gerais. Revista Brasileira de Engenharia Agrícola e 
Ambiental, Campina Grande, v.11, n.6, p.564-570, 2007.

JARAMILLO, J.; BORGEMEISTER, C.; BAKER, P. Coffee berry borer Hypothenemus hampei (Coleoptera: Curculionidae): searching for sustainable control strategies. Bulletin of Entomological Research, Cambridge, v.96, p.223-233, 2006.

MATHIEU, F.; MALOSSE, C.; FRÉROT, B. Identification of the volatile components released by fresh coffee berries at different stages of ripeness. Journal of Agricultural and Food Chemistry. V.46, p.1106-1110, 1998.

MEIRELES, D. F. de; CARVALHO, J. de A.; MORAES, J. C. Avaliação da infestação do Bicho-Mineiro e do crescimento do cafeeiro submetido a diferentes níveis de déficit hídrico. Ciência e Agrotecnologia, Lavras, v. 25, n. 2, p. 371-374, mar./abr. 2001.

PERFECTO I.; RICE R.; GREENBERG R.; VAN DER VOORT M.E. 1996. Shade coffee: a disappearing refuge for biodiversity. Bio-Science, v.46, p.598608, 1996.

RIBEIRO, A.C.; GUIMARÃES, P.T.; ALVAREZ, V.H.V. (Ed). Recomendações para o uso de corretivos e fertilizantes em Minas Gerais. Viçosa: Comissão de Fertilidade do solo do Estado de Minas Gerais, 1999. $359 \mathrm{p}$.

SANTINATO, R.; FERNANDES, A.L.T.; FERNANDES, D.R. Irrigação na cultura do café. 2.ed. Campinas: $\mathrm{O}$ Lutador, 2008. 476 p.

SOTO-PINTO, L.; PERFECTO, I.; CABALLERO-NIETO, J. Shade over coffee: its effects on berry borer, leaf rust and spontaneous herbs in Chiapas, Mexico. Agroforestry Systems, v.37, p.37-45, 2001.

SOUZA, J.C.; REIS, P.R. 1997. Broca do café: histórico, reconhecimento, biologia, prejuízos, monitoramento e controle.
Belo Horizonte, Epamig, 2 ed., 40p. (Boletim Técnico, 50).

STAVER, S.; GUHARAY, F.; MONTERROSO D., MUSCHLER, R.G. Designing pest-suppressive multistrata perennial crop systems: shade-grown coffee in Central America. Agroforestry Systems, v.53, p.151-170, 2001.

TEIXEIRA, C.A.D.; SOUZA, O.; COSTA, J.N.M. Frutos de café "Conilon" brocados por Hypothenemus hampei (Ferrari) (Coleoptera: Scolytidae): Qual a importância de sua queda no decorrer da fase de frutificação? Neotropical Entomology, Piracicaba, v.35, n.3, 2006. 